\title{
Antipruritic effect of cold stimulation at the Quchi Acupoint (LI11) in Mice
}

\author{
Kao-Sung Tsai ${ }^{1,2,3}$, Yung-Hsiang Chen ${ }^{1,2}$, Huey-Yi Chen ${ }^{1,2}$, Ein-Yiao Shen ${ }^{1,2}$, Yu-Chen Lee ${ }^{1,2}$, Jui-Lung Shen ${ }^{4,5}$, \\ San-Yuan $\mathrm{Wu}^{1}$, Jaung-Geng Lin ${ }^{1,2}$, Yi-Hung Chen ${ }^{*^{*}}$ and Wen-Chi Chen ${ }^{1,2^{*}}$
}

\begin{abstract}
Background: Acupuncture and moxibustion are used to treat pruritus and atopic dermatitis. However, whether cold stimulation (defined as that the temperature conducted under skin temperature) of acupoints affects itching in experimental murine models remains unclear.

Methods: The present study was designed to determine the therapeutic effects of different thermal stimulations at the Quchi acupoint (LI11) in a murine model in which scratching behaviour was elicited by subcutaneous injection with a pruritogenic agent (compound 48/80). Male ICR mice were divided into several groups as follows: control (saline), those receiving compound $48 / 80$ and compound $48 / 80$ with various thermal stimulations $\left(5^{\circ} \mathrm{C}-45^{\circ} \mathrm{C}\right.$ ) at LI11 ( $n=6$ per group). The scratch response of each animal to these stimulations was recorded for $30 \mathrm{~min}$. The antipruritic effect of the acupoint was further evaluated in LI11 and sham (non-acupoint) groups ( $n=6$ per group).

Results: Treatment with lower temperature $\left(20^{\circ} \mathrm{C}\right)$ at the LI11 acupoint significantly attenuated compound 48/80-induced scratching; however, this antipruritic effect was not observed with stimulation at the sham point. The expression of c-fos in the neuron of the cervical spine induced by compound 48/80 was suppressed by cold stimulation at LI11. The antipruritic effect of cold stimulation was blocked by ruthium red (RR), a non-selective transient receptor potential (TRP) channel blocker, suggesting that TRP channels may play an important role in the antipruritic effect of cold stimulation at LI11 in mice.
\end{abstract}

Conclusions: This study demonstrated that cold stimulation at LI11 attenuated compound 48/80-induced scratching behaviour in mice, possibly by a TRP-related pathway.

Keywords: Acupuncture, Cold stimulation, Itch, Quchi (LI11), Transient receptor potential

\section{Background}

Acupoint stimulation has been practiced in traditional Chinese medicine for over 2,500 years [1-3]. Several clinical trials have showed that physical stimulation, such as that with needles [4], moxibustion [a traditional Chinese medicine therapy burning moxa made from dried mugwort (Artemisia argyi)], or pressing, at the correct acupoints significantly decrease pruritus [5-8]. Much clinical and pre-clinical data attest to the fact that

\footnotetext{
* Correspondence: yihungchen@mail.cmu.edu.tw; wgchen@mail.cmu.edu.tw 'School of Chinese Medicine, Graduate Institute of Integrated Medicine, Graduate Institute of Acupuncture Science, College of Chinese Medicine, Research Center for Chinese Medicine \& Acupuncture, China Medical University, Taichung, Taiwan

${ }^{2}$ Division of Chinese Acupuncture, Departments of Dermatology, Medical Research, Obstetrics and Gynecology, and Urology, China Medical University Hospital, Taichung, Taiwan

Full list of author information is available at the end of the article
}

acupoint stimulation results in multiple biological responses [9-11]. Several clinic trials of histaminedependent pruritus [12], allergic skin itch [13-15], neurogenic pruritus [16] and refractory uremic pruritus [17] in patients have shown that pruritus is significantly decreased by acupuncture treatment [18-20]. Accordingly, previous studies have shown that Quchi (LI11) is the acupoint commonly used for the treatment of pruritus [5,17].

Compound $48 / 80$ is well known as a peripheral pruritogen. It produces an itch sensation and vigorous scratching behaviour after subcutaneous (s.c.) injection; the itching then causes the degranulation of mast cells and the stimulation of leukotriene B4 production [21]. However, compound $48 / 80$ also elicited the itch sensation in mast cell-deficient mice. Thus, it appears that compound 48/80 
induces scratching behaviour by a mast cell-independent pathway [22]. Moreover, compound 48/80-induced scratching behaviour was inhibited by intrathecal injection with a gastrin releasing peptide receptor antagonist [23]. Compound $48 / 80$ was applied to the murine model used in this study because this experimental system has been verified and is now established as a standard method for evaluating the effect of antiallergic treatment [24-26].

Although acupuncture or moxibustion has been practiced for over 2,500 years, the cooling device was invented only in recent 200 years and was unavailable for the traditional medical treatment. Thus, there were no relevant reports and researches of cold stimulation of the acupoints was addressed. The aim of the present study was to characterise the antipruritic effect of different thermal stimulations at LI11 on compound 48/80induced scratching behaviour in the murine model. The experiment to investigate this was performed using different thermal stimulations. To explore any other viable treatments, in this study, we also assessed whether pre-treatment at LI11 with ruthenium red [RR; a non-selective transient receptor potential (TRP) channel blocker] would alter antipruritic efficacy in mice. Furthermore, the effect of thermal stimulation with $20^{\circ} \mathrm{C}$ at LI11 on neuronal activity and c-fos expression in the cervical spinal cord was investigated using immunohistochemistry (IHC).

\section{Methods}

\section{Animals}

ICR mice (25-30 g, BioLasco Taiwan Co., Ltd., Taiwan) were applied to this study. Mice were maintained at a stable room temperature $\left(22^{\circ} \mathrm{C} \pm 1^{\circ} \mathrm{C}\right)$, humidity $(50 \%-75 \%)$ and intermittent 12-h light and dark cycles for $20 \mathrm{~h}$. Food and water were available ad libitum in the animal facility for at least 4 days before the experiments. The experimental procedures (Figure 1A) were approved by the China Medical University Institutional Animal Care and Use Committee in accordance with the care and use of laboratory animal guidebook from the Chinese Taipei Society of Laboratory Animal Sciences.

\section{Effect of thermal stimulation at the LI11 acupoint on compound 48/80-induced scratching behaviour}

Fixed s.c. doses of compound 48/80 (10 mg/kg) were used to induce scratching. Compound $48 / 80$ was purchased from Sigma Chemical Co. (St. Louis, MO, USA). Male ICR mice were randomised into several groups $(n=6$ per group) as follows: control (saline) without thermal stimulation, those receiving compound 48/80 (s.c.) without thermal stimulation and those receiving compound 48/80 with different thermal stimulations $\left(5^{\circ} \mathrm{C}-45^{\circ} \mathrm{C}\right)$ at LI11. The "cold stimulation" is defined as that the temperature conducted under skin temperature, in the other hand the

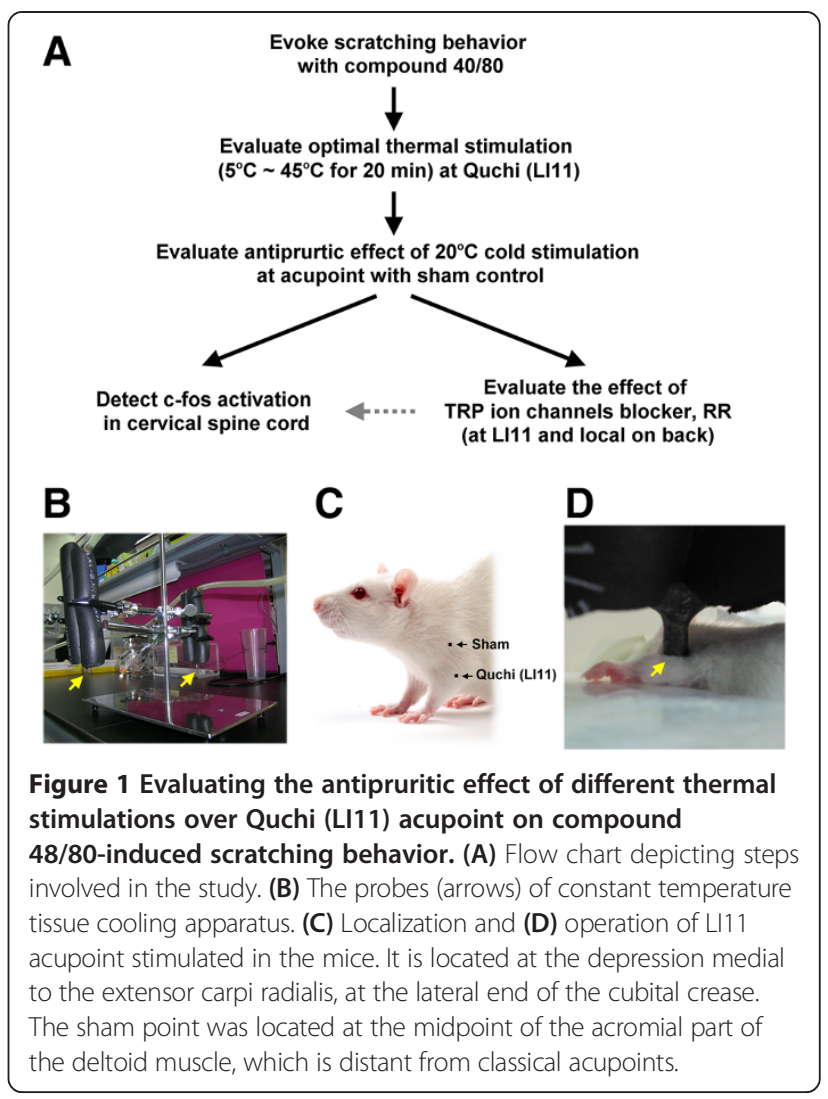

"warm stimulation" is the temperature conducted over skin temperature [27]. The average skin temperature over LI11 of mice in this present study was $28.9^{\circ} \mathrm{C} \pm 1.1^{\circ} \mathrm{C}$.

Mice were individually acclimated in rectangular observation boxes for at least $1 \mathrm{~h}$ and then anesthetised with isoflurane. Different thermal stimulations were performed at LI11 using a constant temperature tissue cooling apparatus (Z3008, Taiwan Advanced Sterilization Technologies Inc., Taiwan) (Figure 1B) for 20 min under anaesthesia. There was only mild erythema in the site on mouse skin after $5^{\circ} \mathrm{C}$ or $45^{\circ} \mathrm{C}$ thermal stimulation. This mild erythema was recovered after one day. Murine LI11 is located at the depression medial to the extensor carpi radialis brevis (at the lateral end of the cubital crease), the equivalent of the human Quchi acupoint (Figures 1C and 1D). After different thermal stimulations, mice were allowed to recover from anaesthesia for $30 \mathrm{~min}$ and were then injected subcutaneously with compound $48 / 80$ on the midline of the neck. The mice were videotaped after injected compound 48/80 over upper back for last $30 \mathrm{mi}$ nutes. Videotapes were reviewed by investigators blinded to treatment. Animals were videotaped and the number of hind leg scratches directed to the back of the neck was counted by another investigator blinded to treatment. Bouts of scratching directed toward the injection site were counted in $5 \mathrm{~min}$ intervals for total $30 \mathrm{~min}$. 
Hind paw movements directed away from the injection site (e.g. ear-scratching), licking or biting of the toes and grooming movements were not counted. We used both parameters, within-bout scratching frequency and number of scratch bouts, however, only total counts of scratch bouts were significantly correlated with the concentration of the pruritic stimulus [28].

\section{Cold stimulation at LI11 and a sham point (non-acupoint)}

Twenty-four mice were further divided into four groups ( $n=6$ per group) as follows: control, those receiving compound 40/80 without thermal stimulation and with cold $\left(20^{\circ} \mathrm{C}\right)$ stimulation at LI11 and cold stimulation at sham (non-acupoint). After thermal stimulation and recovery from anesthesia for $30 \mathrm{~min}$, these mice were injected with compound $48 / 80$ on the midline of the neck. The number of scratches to the back of the neck was counted for $30 \mathrm{~min}$. The sham point was located at the midpoint of the acromial part of the deltoid muscle, which is distant from classical acupoints (Figure 1C) [29].

\section{Alteration of neural activity in the cervical spinal cord after $20^{\circ} \mathrm{C}$ thermal stimulation at LI11}

Compound 48/80 induced c-fos expression in the dorsal horn of the cervical spinal cord. IHC was performed as described previously [30,31]. Two hours after injection with compound 48/80, animals were anesthetised using urethane $[1.2 \mathrm{~g} / \mathrm{kg}$ intraperitoneal (i.p.)]. The cervical spinal cord was then removed and fixed in $4 \%$ paraformaldehyde solution overnight at $4^{\circ} \mathrm{C}$. Tissue samples were transferred to $30 \%$ sucrose solution for at least 3-4 days before sectioning.

Slides were stained with c-fos (Bioss, Woburn, MA, USA) polyclonal antibodies using a Bond-Max autostainer (Leica Microsystems, Singapore). In brief, formalinfixed and paraffin-embedded tissue array specimens were washed in Tris-buffered saline and Tween 20, rehydrated with serial dilutions of alcohol and washed in phosphate-buffered saline (PBS; $\mathrm{pH} 7.2$, which was also used for all subsequent washes) according to the manufacturer's recommended protocol. Slides were stained with previously mentioned antibodies using the fully automated Bond-Max system with heat-induced antigen retrieval and a VBS Refine polymer detection system (Leica Microsystems, Singapore). Diaminobenzidine was used as the chromogen for all IHC reactions [32,33]. Negative controls were obtained by excluding the primary antibody $[34,35]$. The c-fos-positive neurons were observed under a light microscope at high-power field (HPF) magnification [36], and the average number of c-fos-positive neurons was counted single-blind using the imaging software (Image-Pro Plus, Media Cybernetics, Inc., USA).

\section{Effect of the TRP ion channel blocker on thermal stimulation at LI11}

The non-selective TRP ion channel blocker RR was injected s.c. $(0.5 \mu \mathrm{mol} / \mathrm{site})$ at LI11 $5 \mathrm{~min}$ before $20^{\circ} \mathrm{C}$ stimulation. After thermal stimulation and recovery from anaesthesia for $30 \mathrm{~min}$, these mice were injected with compound 48/80 on the midline of the neck. The number of scratches to the back of the neck was counted for $30 \mathrm{~min}$.

\section{Data analysis}

Statistical comparisons were performed using one-way ANOVA followed by all pairwise multiple comparison procedures (Student-Newman-Keuls method). All data were expressed as mean \pm standard error of the mean (SEM). $P<0.05$ was considered to indicate statistical significance.

\section{Results}

\section{Effects of different thermal stimulations at LI11 on} compound 48/80-induced scratching

Mice began scratching 3-5 min after injection with compound 48/80. Scratching behaviour peaked 10-20 min after injection with compound 48/80 and continued for $30 \mathrm{~min}$ during the observation period. The number of hind leg scratches directed to the back of the neck was counted $5 \mathrm{~min}$ intervals for $30 \mathrm{~min}$. Both parameters, within-bout scratching frequency and number of scratch bouts, were shown in Figure 2. Only total counts of scratch bouts were significantly correlated with the concentration of the pruritic stimulus [28].

The data show the time course of within-bout scratching frequency for $5^{\circ} \mathrm{C}$ and $15^{\circ} \mathrm{C}$ (Figure $2 \mathrm{~A}$ ), $20^{\circ} \mathrm{C}$ and $25^{\circ} \mathrm{C}$ (Figure $2 \mathrm{~B}$ ), and $35^{\circ} \mathrm{C}$ and $45^{\circ} \mathrm{C}$ (Figure $2 \mathrm{C}$ ), respectively. The total number of scratches in mice injected with compound 48/80 (290.1 \pm 20.9 bouts/30 min) was significantly higher than that in control mice injected with normal saline $(28.1 \pm 4.4$ bouts $/ 30 \mathrm{~min})$. By contrast, the number of scratches in mice treated with $20^{\circ} \mathrm{C}$ stimulation $(139.8 \pm 31.9$ bouts $/ 30 \mathrm{~min})$, but not $5^{\circ} \mathrm{C}, 15^{\circ} \mathrm{C}, 25^{\circ} \mathrm{C}$, $35^{\circ} \mathrm{C}$, or $45^{\circ} \mathrm{C}$ stimulations, at LI11 was significantly decreased (Figure 2D). These results reveal that $20^{\circ} \mathrm{C}$ is an optimal temperature for cold stimulation at LI11 for attenuating compound 48/80-induced scratching.

Effect of cold $\left(20^{\circ} \mathrm{C}\right)$ stimulation at the sham point did not decrease compound 48/80-induced scratching in mice Cold $\left(20^{\circ} \mathrm{C}\right)$ stimulation at LI11 decreased compound 48/80-induced scratching in mice. In contrast, the stimulation at the sham points did not decrease scratch counts. The mean number of scratches in mice treated with $20^{\circ} \mathrm{C}$ stimulation at the sham point $(292.3 \pm 31.2$ bouts/30 $\mathrm{min}$ ) was similar to that in the compound $48 / 80$ group (Figure 3 ). This result confirms the specific role for the antipruritic effect of acupoint LI11. 

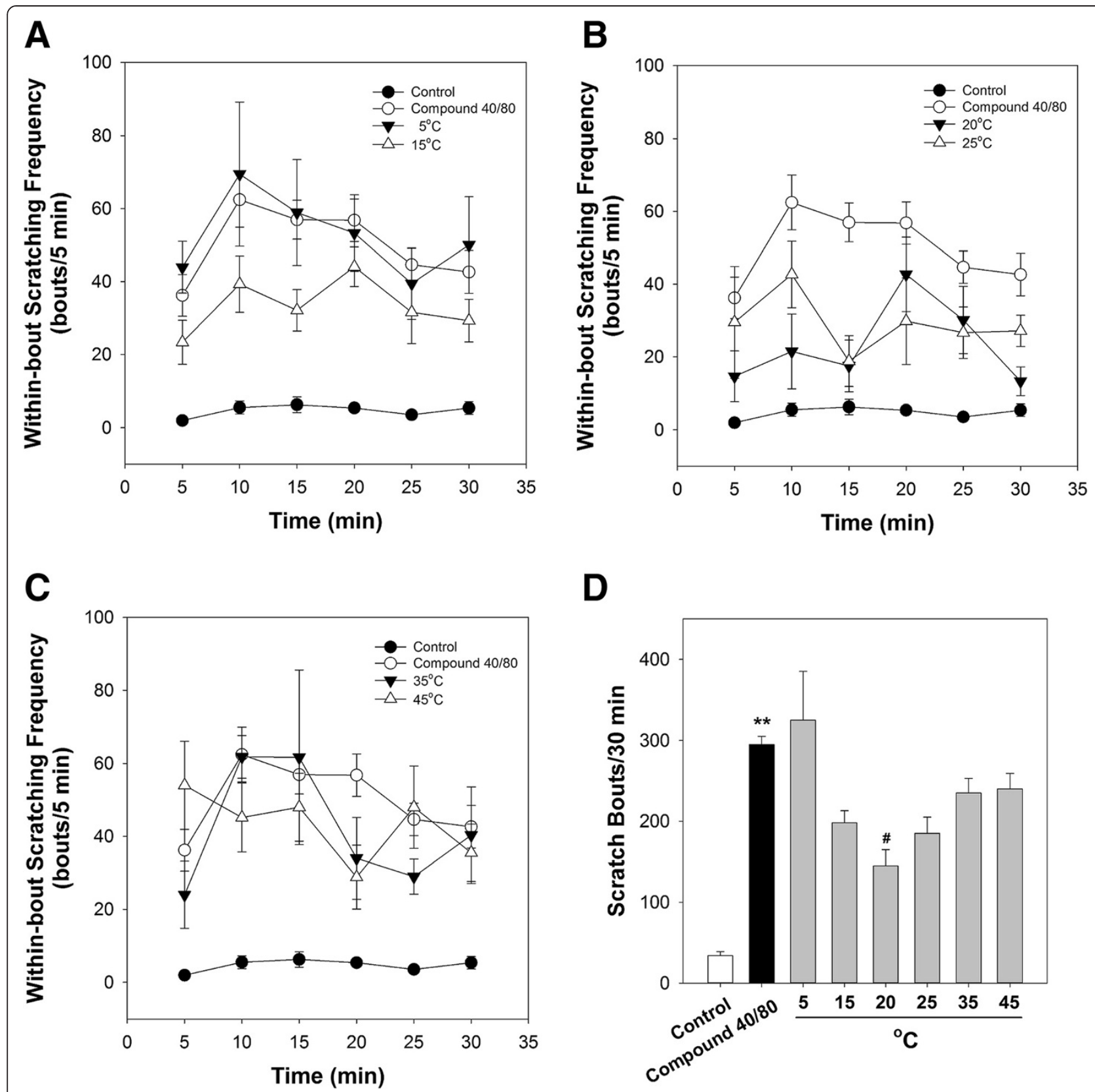

Figure 2 Effects of different thermal stimulations at LI11 for compound 40/80-evoked scratching. Both parameters, within-bout scratching frequency (A) for $5^{\circ} \mathrm{C}$ and $15^{\circ} \mathrm{C}$, (B) $20^{\circ} \mathrm{C}$ and $25^{\circ} \mathrm{C}$, and (C) $35^{\circ} \mathrm{C}$ and $45^{\circ} \mathrm{C}$ and (D) number of scratch bouts, were shown. ${ }^{* *} P<0.01$ compared to control group. ${ }^{\#} P<0.05$ compared to compound $40 / 80$ group).

\section{Cold stimulation at LI11 decreased compound} 48/80-induced c-fos expression in the cervical spinal cord The expression of $\mathrm{c}$-fos was increased as compared to control (saline) group in photomicrographs in the lateral side of the superficial lamina of the dorsal horn of the cervical spinal cord following injection with compound $48 / 80$. However, c-fos expression was rarely detected in the superficial layers of the dorsal horn of mice pretreated with $20^{\circ} \mathrm{C}$ at LI11 (Figure $4 \mathrm{~A}$ and 4B). Since itchrelated scratching was associated with c-fos expression in the superficial layer of the dorsal horn of the spinal cord. IHC analysis revealed that compound 48/80-induced c-fos expression in the cervical spinal cord was decreased after cold stimulation at LI11.

\section{Antipruritic effect of cold stimulation at LI11 was} decreased by the TRP ion channel blocker

Injection with RR at LI11 decreased the antipruritic effect of cold stimulation at LI11. The mean number of scratches in mice treated with $20^{\circ} \mathrm{C}$ stimulation at the 


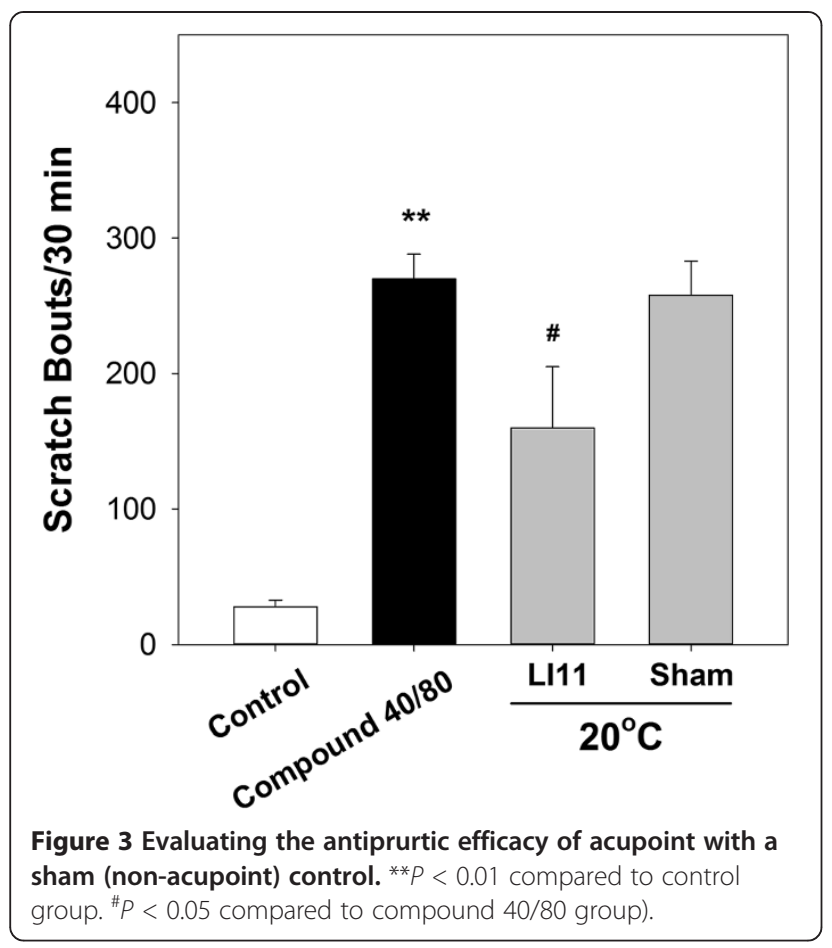

sham point was similar to that in the compound $48 / 80$ group (Figure 5A).

Compound 48/80 may result in histamine release, and RR (a non-selective TRP antagonist) could reduce histamine-related scratching bouts. We further conducted an experiment with RR and compound 48/80 simultaneous injection on same region on upper back of mice. Interestingly, the result showed that local RR administration with compound $48 / 80$ on mouse back significantly reduced scratching bouts caused by compound 48/80 (Figure 5B). Since RR is a non-selective TRP channel blocker, we suggest that TRP channels may play an important role in the antipruritic effect of cold stimulation at LI11 in mice [37-40].

\section{Discussion}

This study was performed to assess the possible antipruritic effects of different thermal stimulations (from temperatures $5^{\circ} \mathrm{C}$ to $45^{\circ} \mathrm{C}$ ) at LI11 on compound $48 / 80$ induced scratching behaviour in a murine model. Compared with traditional moxibustion, which uses high thermal stimulation of acupoints, the application of $20^{\circ} \mathrm{C}$ at LI11 also significantly decreased compound 48/80induced scratching behaviour in mice. To our knowledge, this is the first report to suggest that cold stimulation at LI11 inhibits pruritogen-induced scratching in an animal model. By contrast, cold stimulation at the sham point did not inhibit scratching behaviour. Pre-treatment with RR at LI11 altered the antipruritic effects of $20^{\circ} \mathrm{C}$ thermal
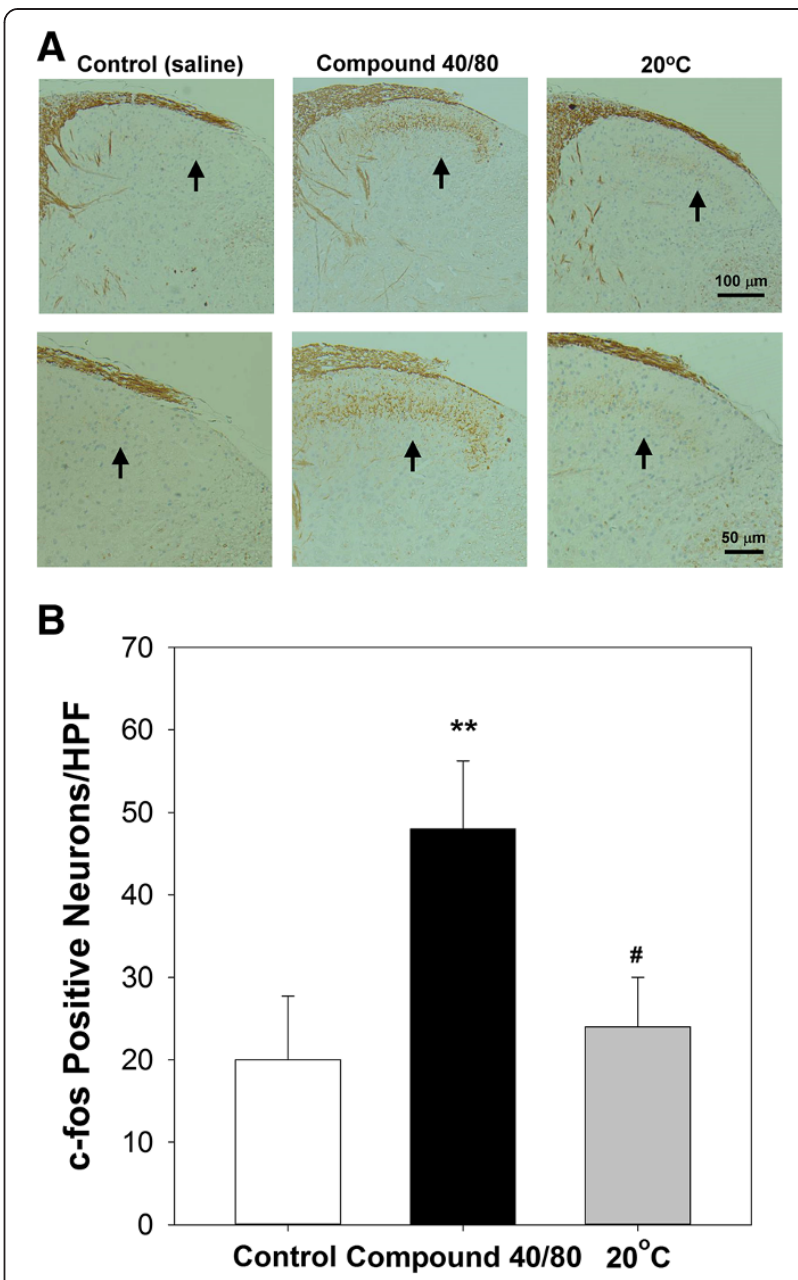

Figure $4 \mathrm{c}$-fos expression in the cervical spinal cord.

(A) Representative photomicrographs and (B) quantitative results of c-fos expression in the spinal cord. The c-fos-positive neurons were observed under a light microscope at high-power field (HPF) magnification, and the average number of c-fos-positive neurons was counted single-blind using the imaging software. ${ }^{* *} P<0.01$ compared to control group. ${ }^{\#} P<0.05$ compared to compound 40/80 group).

stimulation at LI11, suggesting that peripheral TRP ion channels may play a role in this effect. Since compound $48 / 80$, a basic polypeptide with potent mast cell degranulating ability, can induce the flare and weal responses after intradermal injected, this pruritogenic agent is conducted in the study of inducing urticaria and the pruritus of atopic dermatitis [41-43].

The mainly thermosensitive afferents express ion channels are the TRP family which respond at distinct temperature thresholds. The different TRP ion channels activation could also altered the perception of itch or pain. For example, TRPA1, TRPM8, TRPV1, and TRPV3 are key channels that transmit the itch sensation [44]; the TRPV1 and TRPV3 play an important role in histamine dependent itch transduction, but the TRPM8 ion 


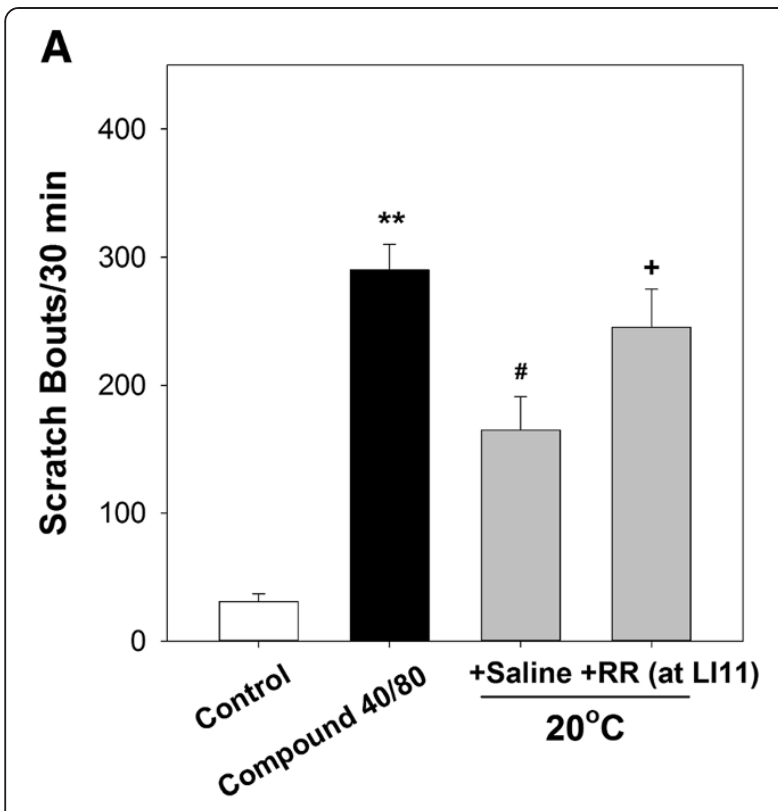

B

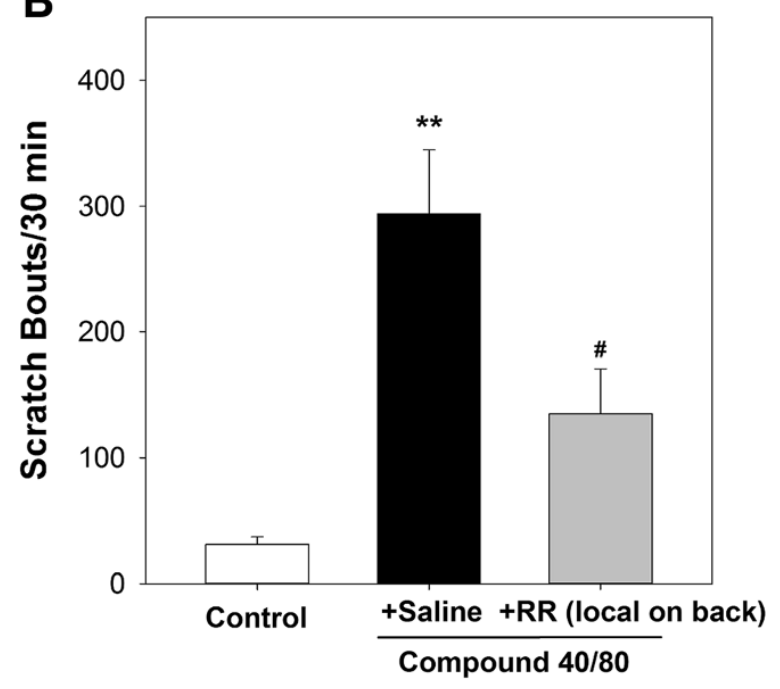

Figure 5 Evaluating the effect of TRP ion channels blocker (Ruthium red; RR). (A) Injection with RR at LI11 decreased the antipruritic effect of cold stimulation at LI11. (B) Local RR administration with compound $48 / 80$ on mouse back significantly reduced scratching bouts. ${ }^{*} P<0.01$ compared to control group. ${ }^{\#} P<0.05$ compared to compound $40 / 80$ group. ${ }^{\dagger} P<0.05$ compared to saline group).

channel is hypothesized to inhibit itch signal transmission [27]. Several studies have shown that various TRP channels modulate the itch sensation and therefore may be therapeutically beneficial $[44,45]$. Similarities are observed between the neural pathways responsible for itching, pain and temperature, which explains the ability of various temperatures to modulate the desire to scratch. Therefore, TRP channels could serve as important but complex clinical targets for pruritus therapy [46]. In the present study, we suggest the different thermal stimulation acting different TRP ion channels which play important role of the antipruritic effect.

During acupuncture, acupoints are stimulated with needles, which may cause receptors to send neural impulses to the spinal cord or act on the pathways to the brain $[47,48]$. This causes the release of neurotransmitters that subsequently modulate functions in the brain and peripheral area $[9,10]$. Previous studies have demonstrated that spontaneous itch-related scratching was associated with $\mathrm{c}$-fos expression in the superficial layer of the dorsal horn of the spinal cord in a rat model [49]. Nuclear c-fos can be induced by pruritogens [30]. The localisation of $\mathrm{c}$-fos in the dorsal horn enables individual neurons of animals activated by noxious inputs to be visualised. IHC analysis revealed that compound 48/80-induced c-fos expression in the lateral side of the superficial layer of the dorsal horn at $\mathrm{C} 2-\mathrm{C} 7$ was decreased after $20^{\circ} \mathrm{C}$ thermal stimulation at LI11.

Pro-inflammatory agents that activate TRP channels in nociceptive neurons can cause neurogenic inflammation and pain. Ceppa et al. reported a major role for TRPV4, which detects osmotic pressure and arachidonic acid metabolites, and TRPA1, which responds to 4-hydroxynonenal and cyclopentenone prostaglandins, in inflammation and pain in mice. Intraductal injection of TRPV4 and TRPA1 agonists increased c-fos expression in spinal neurons, indicative of nociceptor activation, and intraductal TRPA1 agonists also caused inflammation. Deletion of trpv4 or trpa1 gene suppressed c-fos expression and pain behavior. Their results suggest the contributions of TRPV4 and TRPA1 to inflammatory pain [50]. Thus, in this study, c-fos expression on spine is associated with the intense of mice scratch, suggesting it could be altered by the modulation of TRP channels.

Limitations of the current study must be acknowledged. The study was performed using only one pruritogen, which induced murine scratching by mainly histaminedependent pathway, additional pruritogens that activate different scratching signal impulse pathways should be investigated. Moreover, we showed that injection with $R R$ at LI11 decreased the antipruritic effect of cold stimulation at LI11. It should be further clarified what happened to c-fos in the cervical spinal cord after injection with RR at LI11 in future works (schematic representation in Figure 1A). A clinical trial performed on patients with pruritic dermatitis treated with cold stimulation at LI11 may also confirm that cryo-acupuncture is effective in humans.

\section{Conclusions}

Our findings revealed that $20^{\circ} \mathrm{C}$ cold stimulation at LI11 attenuated compound 48/80-induced scratching in mice, suggesting that the efficacy of acupoint stimulation can be 
achieved not only by traditional needles or moxibustion but also by cold stimulation. Therefore, cold stimulation at LI11 is promising as a potentially useful novel noninvasive alternative antipruritic treatment in humans.

\section{Abbreviations}

LI11: Quchi acupoint; RR: Ruthium red; s.c.: Subcutaneous; TRP: Transient receptor potential; IHC: Immunohistochemistry; i.p.: Intraperitoneal; SEM: Standard error of the mean.

\section{Competing interests}

The authors declare that they have no competing interests.

\section{Authors' contribution}

KST and YHC conceived the study, carried out the experiments, analyzed the data, and wrote the manuscript. HYC, EYS, YCL, JLS, SYW, and JGL participated in designing the experiments. YHC involved in drafting the manuscript and gave final approval of the submitted version. YHC and WCC involved in critical revision of important intellectual contents. All authors read and approved the final manuscript.

\section{Acknowledgments}

This work was supported by Taiwan Ministry of Science and Technology (MOST 101-2320-B-039-035-MY3, NSC 101-2320-B-039-035-MY3, and NSC 102-2314-B-039-025), CMU under the Aim for Top University Plan of the Taiwan Ministry of Education, and in part by Taiwan Ministry of Health and Welfare Clinical Trial and Research Center of Excellence (DOH102-TD-B-111-004). K.-S. Tsai and Y.-H. Chen contributed equally to this work.

\section{Author details}

'School of Chinese Medicine, Graduate Institute of Integrated Medicine, Graduate Institute of Acupuncture Science, College of Chinese Medicine, Research Center for Chinese Medicine \& Acupuncture, China Medical University, Taichung, Taiwan. ${ }^{2}$ Division of Chinese Acupuncture, Departments of Dermatology, Medical Research, Obstetrics and Gynecology, and Urology, China Medical University Hospital, Taichung, Taiwan. ${ }^{3}$ Department of Applied Cosmetology, Master Program of Cosmetic Science, Hungkuang University, Taichung, Taiwan. ${ }^{4}$ Department of Dermatology, Taichung Veteran General Hospital, Taichung, Taiwan. ${ }^{5}$ Center for General Education, Feng Chia University, Taichung, Taiwan.

Received: 12 June 2014 Accepted: 16 September 2014

Published: 19 September 2014

\section{References}

1. Park J, Hahn S, Park JY, Park HJ, Lee H: Acupuncture for ankle sprain: systematic review and meta-analysis. BMC Complement Altern Med 2013, 13:55.

2. Zhou HJ, Tang T, Zhong JH, Luo JK, Cui HJ, Zhang QM, Zhou JH, Zhang Q: Electroacupuncture improves recovery after hemorrhagic brain injury by inducing the expression of angiopoietin- 1 and -2 in rats. BMC Complement Altern Med 2014, 14(1):127.

3. Wu SY, Chen WH, Hsieh CL, Lin YW: Abundant expression and functional participation of TRPV1 at Zusanli acupoint (ST36) in mice: mechanosensitive TRPV1 as an "acupuncture-responding channel". BMC Complement Altern Med 2014, 14:96.

4. Wu JN: A short history of acupuncture. J Altern Complement Med 1996, 2(1):19-21.

5. Carlsson CP, Wallengren J: Therapeutic and experimental therapeutic studies on acupuncture and itch: review of the literature. J Eur Acad Dermatol Venereol 2010, 24(9):1013-1016.

6. Lu S: Acupuncture and moxibustion in the treatment of dermatoses. J Tradit Chin Med 1993, 13(1):69-75.

7. Vojdani A: For the assessment of intestinal permeability, size matters. Altern Ther Health Med 2013, 19(1):12-24.

8. Lee KC, Keyes A, Hensley JR, Gordon JR, Kwasny MJ, West DP, Lio PA: Effectiveness of acupressure on pruritus and lichenification associated with atopic dermatitis: a pilot trial. Acupunct Med 2012, 30(1):8-11.
9. Shen J: Research on the neurophysiological mechanisms of acupuncture: review of selected studies and methodological issues. J Altern Complement Med 2001, 7(Suppl 1):S121-127.

10. Han JB, Kim CW, Sun B, Kim SK, Lee MG, Park DS, Min BI: The antipruritic effect of acupuncture on serotonin-evoked itch in rats. Acupunct Electrother Res 2008, 33(3-4):145-156.

11. Pfab F, Athanasiadis Gl, Huss-Marp J, Fuqin J, Heuser B, Cifuentes L, Brockow K, Schober W, Konstantinow A, Irnich D, Behrendt H, Ring J, Ollert M: Effect of acupuncture on allergen-induced basophil activation in patients with atopic eczema:a pilot trial. J Altern Complement Med 2011, 17(4):309-314

12. Pfab F, Huss-Marp J, Gatti A, Fuqin J, Athanasiadis Gl, Irnich D, Raap U, Schober W, Behrendt H, Ring J, Darsow U: Influence of acupuncture on type I hypersensitivity itch and the wheal and flare response in adults with atopic eczema - a blinded, randomized, placebo-controlled, crossover trial. Allergy 2010, 65(7):903-910.

13. Belgrade MJ, Solomon LM, Lichter EA: Effect of acupuncture on experimentally induced itch. Acta Derm Venereol 1984, 64(2):129-133.

14. Lundeberg $\mathrm{T}$, Bondesson $\mathrm{L}$, Thomas M: Effect of acupuncture on experimentally induced itch. Br J Dermatol 1987, 117(6):771-777.

15. Cabioglu MT, Cetin BE: Acupuncture and immunomodulation. Am J Chin Med 2008, 36(1):25-36.

16. Stellon A: Neurogenic pruritus: an unrecognised problem? A retrospective case series of treatment by acupuncture. Acupunct Med 2002, 20(4):186-190.

17. Kim KH, Lee MS, Choi SM: Acupuncture for treating uremic pruritus in patients with end-stage renal disease: a systematic review. J Pain Symptom Manage 2010, 40(1):117-125.

18. Liao WL, Tsai FJ: Personalized medicine: A paradigm shift in healthcare. BioMedicine 2013, 3(2):66-72.

19. Hsieh CL: Acupuncture as treatment for nervous system diseases. BioMedicine 2012, 2(2):51-57.

20. Chen YS: Effects of electrical stimulation on peripheral nerve regeneration. BioMedicine 2011, 1(1):33-36.

21. Andoh T, Kuraishi Y: Intradermal leukotriene B4, but not prostaglandin E2, induces itch-associated responses in mice. Eur J Pharmacol 1998, 353(1):93-96.

22. Inagaki N, Igeta K, Kim JF, Nagao M, Shiraishi N, Nakamura N, Nagai H: Involvement of unique mechanisms in the induction of scratching behavior in BALB/c mice by compound 48/80. Eur J Pharmacol 2002 448(2-3):175-183.

23. Sun YG, Chen ZF: A gastrin-releasing peptide receptor mediates the itch sensation in the spinal cord. Nature 2007, 448(7154):700-703.

24. Patel KN, Dong X: An itch to be scratched. Neuron 2010, 68(3):334-339.

25. Zhao P, Hiramoto T, Asano Y, Kubo C, Sudo N: Chronic psychological stress exaggerates the compound 48/80-induced scratching behavior of mice. Pharmacol Biochem Behav 2013, 105:173-176.

26. Akimoto Y, Furuse M: SCH23390, a dopamine D1 receptor antagonist, suppressed scratching behavior induced by compound $48 / 80$ in mice. Eur J Pharmacol 2011, 670(1):162-167.

27. Bharate SS, Bharate SB: Modulation of thermoreceptor TRPM8 by cooling compounds. ACS Chem Neurosci 2012, 3(4):248-267.

28. Nojima H, Carstens E: Quantitative assessment of directed hind limb scratching behavior as a rodent itch model. J Neurosci Methods 2003, 126(2):137-143.

29. Pfab F, Hammes M, Backer M, Huss-Marp J, Athanasiadis GI, Tolle TR, Behrendt H, Ring J, Darsow U: Preventive effect of acupuncture on histamine-induced itch: a blinded, randomized, placebo-controlled, crossover trial. J Allergy Clin Immunol 2005, 116(6):1386-1388.

30. Inan S, Dun NJ, Cowan A: Nalfurafine prevents 5'-guanidinonaltrindoleand compound 48/80-induced spinal c-fos expression and attenuates 5 '-guanidinonaltrindole-elicited scratching behavior in mice. Neuroscience 2009, 163(1):23-33.

31. Chen YH, Yang HY, Lin CH, Dun NJ, Lin JG: Electroacupuncture Attenuates 5'-Guanidinonaltrindole-Evoked Scratching and Spinal c-Fos Expression in the Mouse. Evid Based Complement Alternat Med 2013, 2013:319124.

32. Lin FY, Lin YW, Huang CY, Chang YJ, Tsao NW, Chang NC, Ou KL, Chen TL, Shih CM, Chen YH: GroEL1, a heat shock protein 60 of Chlamydia pneumoniae, induces lectin-like oxidized low-density lipoprotein receptor 1 expression in endothelial cells and enhances atherogenesis in hypercholesterolemic rabbits. J Immunol 2011, 186(7):4405-4414. 
33. Yin WH, Chen YH, Wei J, Jen HL, Huang WP, Young MS, Chen DC, Liu PL: Associations between endothelin-1 and adiponectin in chronic heart failure. Cardiology 2011, 118(4):207-216.

34. Yang TL, Lin FY, Chen YH, Chiu JJ, Shiao MS, Tsai CS, Lin SJ, Chen YL Salvianolic acid B inhibits low-density lipoprotein oxidation and neointimal hyperplasia in endothelium-denuded hypercholesterolaemic rabbits. J Sci Food Agric 2011, 91(1):134-141.

35. Chen WC, Wu SY, Liu HP, Chang CH, Chen HY, Chen HY, Tsai CH, Chang YC, Tsai FJ, Man KM, Liu PL, Lin FY, Shen JL, Lin WY, Chen YH: Identification of melamine/cyanuric acid-containing nephrolithiasis by infrared spectroscopy. J Clin Lab Anal 2010, 24(2):92-99.

36. Zhang HH, Chen J, Xia CM, Jiang MY, Wang J, Cao YX, Shen LL, Wang MY, Zhu DN: Protective effects of electroacupuncture on cardiac function in rats subjected to thoracic surgery trauma. Brain Res Bull 2012, 89(1-2):71-78

37. Imamachi N, Park GH, Lee H, Anderson DJ, Simon MI, Basbaum Al, Han SK: TRPV1-expressing primary afferents generate behavioral responses to pruritogens via multiple mechanisms. Proc Natl Acad Sci U S A 2009, 106(27):11330-11335.

38. Yamamoto-Kasai E, Imura K, Yasui K, Shichijou M, Oshima I, Hirasawa T, Sakata T, Yoshioka T: TRPV3 as a therapeutic target for itch. J Invest Dermatol 2012, 132(8):2109-2112.

39. Zhang H, Chen X, Zhang C, Zhang R, Lao L, Wan Y, Yi M: Comparison of electroacupuncture in restrained and unrestrained rat models. Evid Based Complement Alternat Med 2013, 2013:404956.

40. Zhang R, Lao L, Ren K, Berman BM: Mechanisms of acupunctureelectroacupuncture on persistent pain. Anesthesiology 2014, 120(2):482-503.

41. Church MK, Clough GF: Human skin mast cells: in vitro and in vivo studies. Ann Allergy Asthma Immunol 1999, 83(5):471-475.

42. Fadel R, Ramboer I, Chatterjee N, Rihoux JP, Derde MP: Cetirizine inhibits bradykinin-induced cutaneous wheal and flare in atopic and healthy subjects. Allergy 2000, 55(9):888-891.

43. Smith CH, Atkinson B, Morris RW, Hayes N, Foreman JC, Lee TH: Cutaneous responses to vasoactive intestinal polypeptide in chronic idiopathic urticaria. Lancet 1992, 339(8785):91-93.

44. Lucaciu OC, Connell GP: Itch sensation through transient receptor potential channels: a systematic review and relevance to manual therapy. J Manipulative Physiol Ther 2013, 36(6):385-393.

45. Valdes-Rodriguez R, Kaushik SB, Yosipovitch G: Transient receptor potential channels and dermatological disorders. Curr Top Med Chem 2013, 13(3):335-343.

46. Kuraishi Y: Potential new therapeutic targets for pathological pruritus. Biol Pharm Bull 2013, 36(8):1228-1234.

47. Wang SM, Kain ZN, White P: Acupuncture analgesia: I. The scientific basis. Anesth Analg 2008, 106(2):602-610.

48. Zhao ZQ: Neural mechanism underlying acupuncture analgesia. Prog Neurobiol 2008, 85(4):355-375.

49. Nojima H, Carstens MI, Carstens E: c-fos expression in superficial dorsal horn of cervical spinal cord associated with spontaneous scratching in rats with dry skin. Neurosci Lett 2003, 347(1):62-64.

50. Ceppa E, Cattaruzza F, Lyo V, Amadesi S, Pelayo JC, Poole DP, Vaksman N, Liedtke W, Cohen DM, Grady EF, Bunnett NW, Kirkwood KS: Transient receptor potential ion channels V4 and $\mathrm{A} 1$ contribute to pancreatitis pain in mice. Am J Physiol Gastrointest Liver Physiol 2010, 299(3):G556-571.

\section{Submit your next manuscript to BioMed Central and take full advantage of:}

- Convenient online submission

- Thorough peer review

- No space constraints or color figure charges

- Immediate publication on acceptance

- Inclusion in PubMed, CAS, Scopus and Google Scholar

- Research which is freely available for redistribution

Submit your manuscript at www.biomedcentral.com/submit
C Biomed Central 